\title{
Implementation of industry 4.0 to achieve sustainable manufacturing in steel industry: A case study
}

\author{
Mayank Indoria \\ Department of Mechanical Engineering, MBM Engineering College, J.N.V University, Jodhpur-342003, India. \\ Pradeep Kumar* \\ Department of Mechanical Engineering, MBM Engineering College, J.N.V University, Jodhpur-342003, India. \\ Yukta Panwar \\ Department of Mechanical Engineering, MBM Engineering College, J.N.V University, Jodhpur-342003, India. \\ Tapish Sharma \\ Department of Mechanical Engineering, MBM Engineering College, J.N.V University, Jodhpur-342003, India. \\ *Corrosponding author email: Email: pkmech1992@gmail.com
}

\begin{abstract}
Sustainable manufacturing has been a popular topic of research for quite some time now. There are various concepts and ideas which have claimed to have a significant impact on sustainability of the manufacturing industry like lean, green and agile manufacturing. Industry 4.0 is the latest and by far the one with the maximum potential of changing the manufacturing sector forever. It is rightly called as "the fourth industrial revolution". It is a wide concept which covers many states of the art technologies like the Internet of Things (IoT), Artificial Intelligence, Big Data, Augmented reality etc. But like every big revolution, it is to face many challenges also. In this review, we are looking at this 'yet in infancy' concept and its role in achieving a sustainable manufacturing sector as discussed by researchers. Different scholars have come up with different challenges to implementation of I4.0 which they thought to be of some significance. There is going to review such challenges making a list of 13 such challenges. Then, it also throws some light on the new challenge faced by all of humanity in the form of SARS-CoV-2 pandemic and how it is affecting the manufacturing sector.
\end{abstract}

Keywords: Industry 4.0; Sustainable Manufacturing; Sustainability; Manufacturing

\section{Introduction}

Manufacturing industries are forced by increasing challenges such as resource depletion, economic stagnation, human beings pursuing higher life quality and stricter laws and environment protection policies. Sustainable manufacturing has intended to empower the companies to cope with such challenges and guide them to stand out in the competitive market today. Therefore, manufacturers are now tending to reset to manufacturing processes and manufactured products that minimize environmental impacts while considering social and economic dimensions. Indian manufacturing units, especially SMEs, have long been avoiding any big transformation. The ongoing pandemic has disrupted the global as well as domestic demand and supply chains [1]. Recent data released by GoI shows that manufacturing is the worst performing sector (at -39.3\%) after Construction. At this point of time, the long pending restructuring of the processes and methods has become absolutely necessary. Further continuing with the traditional manufacturing techniques without adapting to the new order might prove to be a recipe for disaster. Now the question arises how a manufacturing industry should approach towards achieving goals offered by sustainable manufacturing? How to implement these changes in the current system? How to make complete use of industry 4.0 ? its focusing on the implementation of industry 4.0 in order to enhance sustainability in Indian manufacturing industries. It also focuses on the challenges faced by Indian manufacturing industries in implementation of industry 4.0 and the methods that can be used in obtaining maximum output by implementation of 
Industry 4.0 Industry 4.0 is based on the establishment of smart factories, smart products, and smart services embedded in an internet of things. Sustainable manufacturing or Green manufacturing focuses on energy efficiency, conservation of resources and low waste production and reduces environmental impact. In this process we need to identify, quantify, assess, and manage the flow of environmental waste with the goal of ultimately reducing the environmental impact to that of the self-recovery capability of the Earth could deal with while also trying to maximise resource efficiency . The OECD Sustainable Manufacturing Toolkit illustrates three aspects of sustainability as Environmental, Economic and Social. The 17 well known SDGs (Sustainable Development Goals) of the UN (United Nations) summarizes the need of the hour in a very simple manner and for all three aspects. These SDGs, since their adoption by the UN, have served as the guiding light for policy makers across the globe. Adoption of the SDGs was, according to the UN, "a universal call to action to end poverty, protect the planet and ensure that all people enjoy peace and prosperity by 2030". In this journey to improve sustainability in all aspects of life, many challenges have come our way and many are waiting for us in the journey ahead. We have reviewed such challenges mentioned by earlier researchers. In the end we have reviewed the current situation of COVID-19 pandemic in light of challenges it offers to our agenda of achieving SDGs by 2030.

Selection of the literature to be reviewed by searching on google scholar with keywords, "Sustainability in manufacturing" OR "Industry 4.0 Sustainability" OR “Sustainable manufacturing" OR "Industry 4.0 challenges".

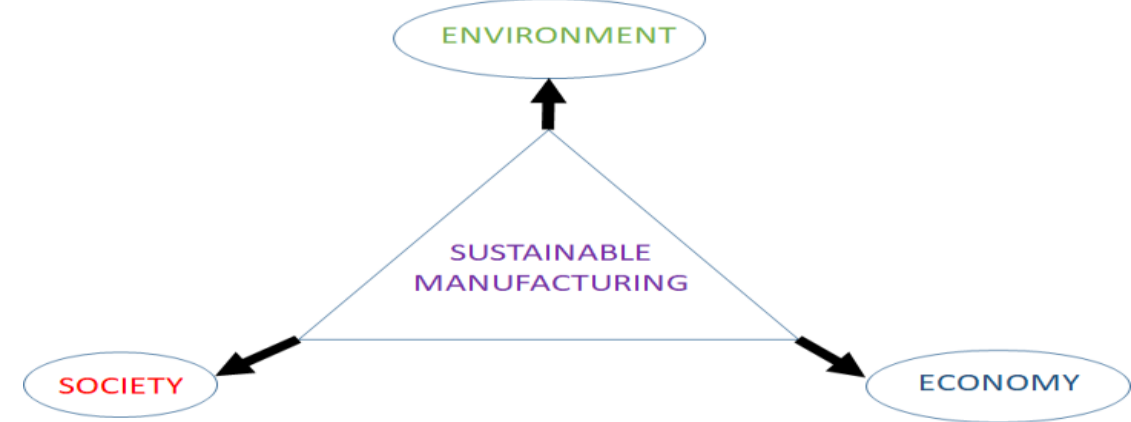

Fig 1. Sustainability in manufacturing

\subsection{Industry 4.0}

The evolution and rapid growth in science has brought rapid changes in industrialization. It all started with high-speed manufacturing around the 1800s with growth in steam power and iron production. The introduction of mass production, assembly line and electricity in the second phase of revolution which were further aided by electronics and IT for automation in production in phase three. Now the fourth phase of industrial revolution (Industry 4.0) brings further advancement to these preexisting procedures. Its main focus is the application of flexible automation, cyber-physical systems, (industrial) Internet of Things, sensors, collaborative and cognitive robotics, cloud computing, big data, computer modelling and simulations, additive manufacturing, 3D printing. Industry 4.0 brings the idea of computer integrated manufacturing (CIM) and flexible manufacturing system (FMS). There are nine key technologies which define and form base for implementation of Industry 4.0. Using these technologies, we can compete with the fast-changing industrial processes and surrounding (individual, social and environment). 


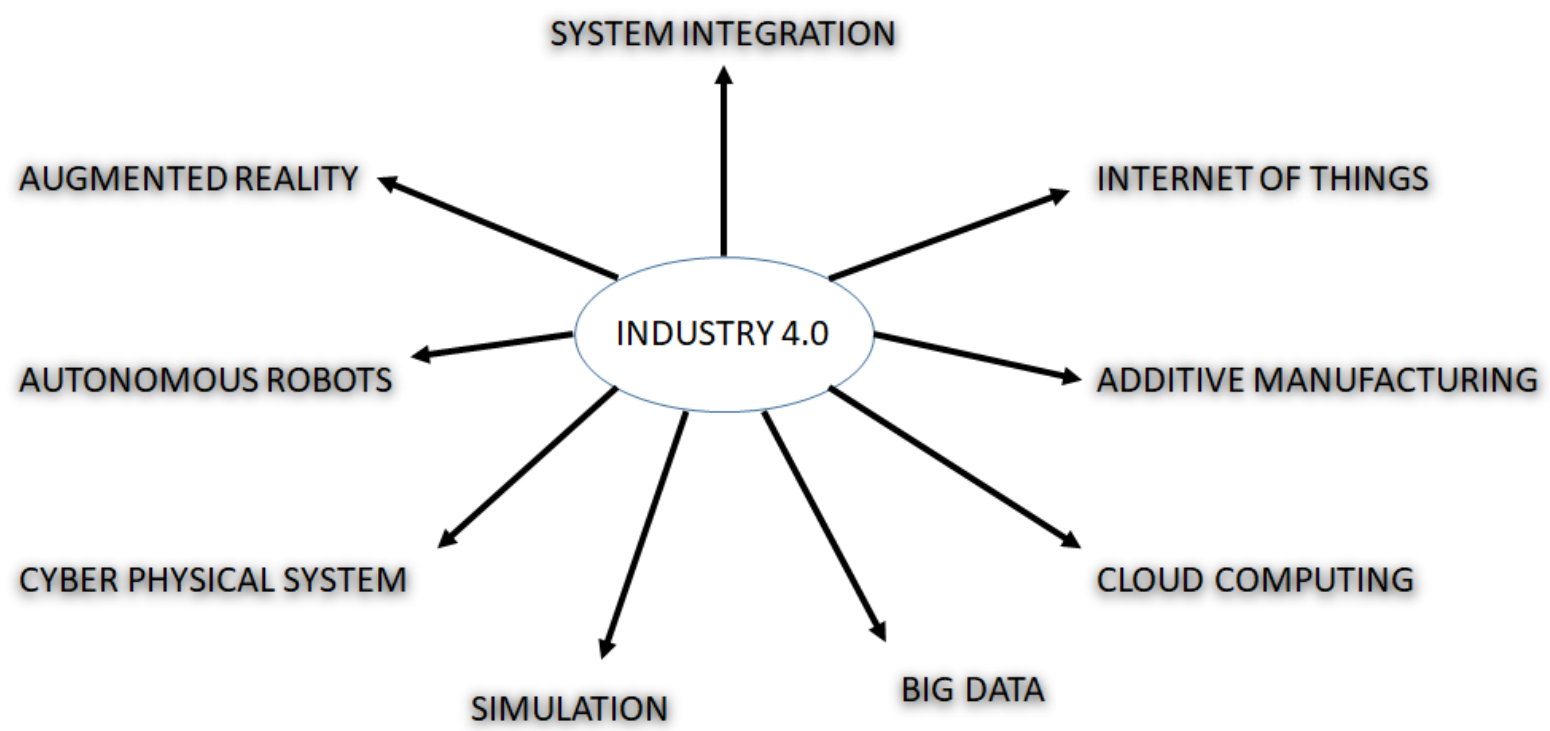

Fig 2. Technologies offered by Industry 4.0 and their use to achieve sustainability in manufacturing

\subsection{Internet of things}

Industrial internet of things (IIoTs) connect machines with each other and with industrial application by internet so that machines can interact with each other to share information. Internet of things helps in easier collection of data and analysis, which can be used to develop better manufacturing processes, waste management, energy conservation. Through continuous monitoring of the process better decisions like product quality, product life, product cost reduction, pollution, faults in process can be made to obtain sustainability in manufacturing.

\subsection{Cloud computing}

Cloud Computing is a new technology which helps in easy storage of data over the internet, which provides easier computing and access of data from all over the world via internet. Cloud computing provides a major role in sustainable manufacturing as the hardware storage can be replaced with remote storage, which improves process timing and helps in conservation of energy. Cloud computing provides easy access of available data, transparency and responsiveness of the supply chain and easy sharing of important data.

\subsection{Big data}

Big data analyst helps in gathering relevant data from a large set of data. It helps in identifying performance of each component, their limitations and future preventive actions in order to remove future production issues. Big data uses the data collected by various devices connected through IOT, which can be analyzed to get information and trends. This information can be used to increase the efficiency of AI (artificial intelligence) and better automation of machines. This increase in efficiency of machines adds to sustainability in manufacturing by reducing complexity and overprocessing.

\subsection{Simulation}

Simulation systems allow virtual replication of a process as well the evaluation of the impact produced by changes in manufacturing variables. They allow assessment of variables before making a prototype. Simulation improves the quality of research and development activities. Simulation helps in removal of defects from the product and process in an early stage. It helps in better product development. Simulation and modelling save time, energy and raw material. Simulation reduces the chances of failure of the product by providing early correction of defects (development stages). This helps in 
testing of new procedures without disturbing the manufacturing process. It allows the time taken in development of a product, so that it can be quickly made available in the market.

\subsection{Autonomous robots}

Autonomous robot is a mechanical device which can work with high efficiency and autonomy by utilizing human skills and with proper safety measures. This technology helps in better utilization of human skill by reducing physical burden. Autonomous robots help in maintaining high manufacturing standards and provide consistency in the finished product by removing human error. It helps In meeting fast growing demands of the market by increasing the production speed. This adds up in saving energy, human effort and reduces the waste material (defective products) in manufacturing.

\subsection{Augmented reality}

Augmented reality (AR) is an interactive experience of a real-world environment. It superimposes a computer-generated image on users in the real world providing a composite view. This real-world scenario helps in gathering the information about the problem that the product can face in the market. It narrows the gap between workforce and digital technology. It improves versatility and efficacy of the product.

\subsection{Cyber security and CPS}

As we move from the physical systems towards IoT and cloud computing, security of this information becomes important. Cyber security helps in protection of this information and provides a platform which the user can trust. Cyber physical system (CPS) improves machine- human interface by improving better exchange of information/data. Cyber physical system is a computer system in which a mechanism is controlled or monitored by computer-based algorithms. This helps in solving problems which are difficult for humans.

\subsection{System integration}

System integration is defined in engineering as the process of bringing together the component subsystems into one system and ensuring that the subsystems function together as a system. It brings integration throughout the supply chain, manufacturing, management and business system. System integration brings visibility and improves communication between different levels of the company. This improves work culture and helps in waste and energy control by integrating information from all parts of the organization.

\subsection{Additive manufacturing (3d Printing)}

Additive manufacturing is a technology used to produce prototypes by layer by layer deposition of the material. This requires 3D design and modelling. This process produces prototypes with very high dimensional accuracy and speed. Additive manufacturing reduces the amount of material used in prototype manufacturing. Product variations are easier to achieve, thus product flexibility can be achieved to match the market demands. Time taken to develop a prototype is reduced and the product can reach the market rapidly.

\section{Challenges}

Although it is expected of Industry 4.0 to cope up with various challenges faced by traditional industry, there are challenges in implementing this 'yet in infancy' technology especially in developing countries like India. There have been some initiatives from the government attempting to minimize the resistance offered in the form of these challenges. "Make in India" being one such effort, could not achieve what it was intended to. Although, The Gross Value Added (GVA) at basic current prices from the manufacturing sector in India grew at a CAGR of 5 per cent during FY16 and FY20 as per the annual 
national income published by the Government of India (if we do not consider the post covid figures assuming that things will almost restore once the vaccine is out), it is far less than what is needed to achieve the ambitious target of 5 trillion economy set by GoI[8]. For that to happen, traditional manufacturing must give way to the smart one. I4.0 will face many challenges on its way to becoming the new normal. One most obvious hurdle is lack of funds for the high initial cost of I4.0 technology. Another challenge is lack of education and expertise in this field. In this review, we are going to consolidate a list of such challenges which can be easily overlooked otherwise. For this purpose, we have made references to several published works on this topic [9].

\subsection{Lack of motivation from customers/OEMs on adopting sustainable manufacturing processes}

Businesses are not run by businessmen. They are run by consumers. The demand which is created by the common public feeds the machines in the industries. India is also a consumer-based economy because of its high population. Whole world looks towards us for a potential market. It is necessary for the customers to be interested in sustainable manufacturing if the industry is to be changed. But as we see in India, that level of public awareness is not there. This offers hindrance to the change even before it begins. Industries are not in general motivated to bring about the required change [2].

\subsection{High initial cost of I 4.0 technology}

Industry 4.0 is a conglomeration of many states of the art technologies like IoT, robotics, artificial intelligence, additive manufacturing, nanotech, biotech etc. Currently, India has no significant milestone in any of these. Development of all this will require very high capital investments. Such requirements stop small scale businesses from becoming a part of the revolution [2][3][4].

\subsection{Lack of interest from investors in a new technology}

Even those who have the required funds may not choose to invest in such new technologies. There is a lot of analysis before one invests. Any kind of uncertainty in returns drives the investors away. The cost will be compared to the losses in production while updating the technologies and the time required to recover the losses and investments from the new technology. I4.0 will have to go and pass through many such financial tests [2][3].

\subsection{Lack of infrastructure:}

India, despite its continuous growth in recent decades, still lacks both physical and digital infrastructure. Availability of roads, electricity, internet connectivity (even if available, it has very low speeds) is still not upto the mark. Without good digital infrastructure, technologies like IoT will not be of any use. And without physical infrastructure, it would not be possible to convince global players to manufacture in India [[2][3][4].

\subsection{Lack of management/leadership support for sustainable future:}

India has a strong leadership for traditional manufacturing like TATAs, Mittal etc. but it lacks such leadership when we look for sustainable manufacturing. I4.0 technology will bring about a lot of organizational changes to the industries. Decision making will take place at the factory shop floor. Decentralization of authority will attract some resistance from the leaders of traditional mindsets [2][3][4].

\subsection{Lack of well-trained workforce for cyber-physical systems:}

Upskilling of the existing workforce as well as the newcomers is a major challenge. The newer technologies will demand more skilled employees. Educational institutes will have to start updating 
their course structures according to the new order. A high-level collaboration is needed between industries, educational institutes and the government [2][3][4].

\subsection{Lack of database management system:}

There will be an enormous amount of data generated through various sensors attached to the machines. This data will be of no use if it is not managed and analysed properly. Most companies have neither such storage capacity for data nor the expertise in data analysis. A slight mistake in data management may lead to wrong decisions. Data analysts will have to be hired for the task [3].

\subsection{Interoperability issues:}

Updating of existing machines by integrating them with the cyber-physical systems will have to be smooth. This will offer a significant technical challenge. Researchers have pointed out the need of interoperability at multiple levels. For proper functioning of the interconnected cyber-physical systems, seamless integration of different technologies will have to be ensured. This is again a major technological challenge before the sector [2][3].

\subsection{Cyber Security issues:}

The smart manufacturing systems are interconnected through networks throughout the life cycle of the product. This makes it a necessity to make every node of those networks secure with help of end to end encryption [5]. quotes India's Cybercrime Survey Report 2017, stating, "79\% of corporations in India have acknowledged cyber security as one of the top five business risks". Laws related to privacy and cyber security need to be strengthened and made more elaborate [2][3][4].

\subsection{Fear of unemployment/reduction in employment:}

The current jobs in the manufacturing industries require a skill set completely different from what will be needed in the future when I4.0 rolls out. Growing automation has already taken a toll on human employment. Many jobs will be robotized in the endeavor to gain sustainability in manufacturing by Industry4.0. Although new opportunities will open for highly skilled data analysts and data scientists, still it will be far less than no. of jobs lost. Problem of unemployment for unskilled and semi-skilled labour in the manufacturing sector will rise[2][3][4].

\subsection{Multilingualism}

For a country as diverse as India, it is even more difficult to gain uniformity and standardization in all forms and at all levels. The new physical-cyber system tools (e.g.AI) which will carry forward the I4.0 revolution will have to use the local languages of the interiors of the nation if we want an all-rounder performance in this endeavor to achieve sustainability in manufacturing. Only then will the term 'smart manufacturing' stand true to its meaning [3].

\subsection{Safety in human robot collaboration (coot)}

The robots which are supposed to help the manufacturing industry achieve sustainability, should be able to interact with humans in a safe manner. There should be no operational health and security threats involved in the interaction. While implementing the CPS and the robotic technology, it should be made sure that there are no hazard threats (mechanical, electrical, thermal, vibrational, radiation, noise etc) in the industry[2][3][4].

\subsection{Challenge due to COVID-19 pandemic}

"The world has seen many crises over the past 30 years, including the Global Financial Crisis of 200709. 
Each has hit human development hard but, overall, development gains accrued globally year-on-year. COVID-19, with its triple hit to health, education, and income, may change this trend", says UNDP Administrator Achim Steiner [6].

The above statement tells us much about the nature and intensity of the impact of the pandemic on the world order. In the light of the reports of GDP of India shrinking by $23.9 \%$ in the first quarter of the FY 2020-21, the 2030 Agenda of the UN and the SDGs seem deferred. Manufacturing is the worst hit sector at $-39.3 \%$. Supply chains and production systems are globally disrupted. Demand is on a steep downfall. Manufacturing units are either closed or running at less than half of their capacity. This extraordinary situation shows us how vulnerable our current industries are to uncertainty. There is an immediate need for improvement of the systems so that they can be made more sustainable.

There are certain products which are high on demand or rather needed on an emergency basis during the pandemic. Demand for several items like masks, sanitizers, gloves, PPE kits, thermal scanners, ventilators etc. is skyrocketing. Big manufacturers like GE, Ford, Mahindra etc have come up to start manufacturing ventilators catering to the needs of the society. This is an example of how flexibility in manufacturing can help in ensuring sustainability in society. India manufactured 60,000 ventilators indigenously in 3 months, starting from zero. If not for the FMS, this wouldn't have been possible so easily [7].

Various organizations have started making pandemic preparedness plans. Culture of work from home is gaining momentum, helping both the employee and employer save money. Manufacturing sector will also have to find a way to become "pandemic proof".

\section{Case study: ABC Steel India}

Steel industry is traditionally seen as one of the worst industries in terms of environmental impact. $A B C$ steel has totally changed this perception by their continuous efforts to fulfill the dream of a sustainable future in manufacturing. Let us see how $\mathrm{ABC}$ Steel pulled off such a great task despite the challenges which we have discussed above.

First let have a glance over the impact which ABC Steel has created through some facts :

The Approach:

$\mathrm{ABC}$ has followed a fourfold approach towards sustainability. The four pillars are :

1.Governance 2. Material issues 3.Sustainability performance 4.Sustainability disclosures

Governance:

Policy making

They have worked on multiple levels of governance in the company. First, they have laid out policies in different areas of operations keeping up with the Tata Code of Conduct which shows commitment towards sustainability. These include Sustainability Policy, Environment Policy, Climate Change Policy for Tata Companies, Energy Policy, Biodiversity Policy, Corporate Social Responsibility and Accountability Policy, Affirmative Action Policy, Social Accountability Policy, Responsible Supply Chain Policy, Safety Principles \& Occupational Health Policy and Human Resource Policy.

Boards and committees

They have formed committees which are assigned the work of reviewing various performance indicators of the company periodically. Safety, Health and Environment (SHE) Committee reviews the SHE performance quarterly for all key performance indicators across locations. CSR \& Sustainability Committee reviews the long-term sustainability strategy and CSR activities of the organization. They also have many committees on corporate level which include Apex Safety Committee, Apex 
Environment Committee, Apex Human Resource Development Committee, Apex CSR Committee, Apex R\&D Committee etc. These are chaired by senior leadership of the company.

Engagement in External Forums

Senior leadership engages with various national and international forums on sustainability issues. Some of international forums are World Steel Association, United Nations Global Compact (UNGC), World Economic Forum (WEF), Global Reporting Initiative (GRI), the International Integrated Reporting Council (IIRC), Task Force on Climate related Financial Disclosures (TCFD), International Union for Conservation of Nature (IUCN). Among National forums are Confederation of Indian Industry (CII), The Energy and Resources Institute (TERI), Indian Institute of Metals (IIM)

Material Issues:

ABC Steel has classified their material issues in four broad categories namely Economic, Environmental, Social and Governance. They have further defined different issues in each category. For example, Economic-Material issues have business growth, long term profitability and product quality, price offering and delivery as the different issues which are taken care of by planning individually and dependently of each other. Environmental-Material issues have renewable and clean energy, waste management, water management, Energy efficiency, supply chain sustainability as the key issues. There are Social-Material issues which include occupational health and safety, Labor relations, Local sourcing of labor, Drinking water etc. In Governance-Material issues they have included things like Going beyond the compliance and setting trends for the future generations, Greater stakeholders' engagement, technical knowledge transfer and capacity building for relevant partners.

All these identified issues are worked upon, and a set of ambitions is set for every issue. They have worked from the top leadership to the ground level to ensure these things are taken seriously and worked upon with enthusiasm.

Sustainability Performance:

They have identified six capitals namely Financial, Human, Intellectual, Manufactured, Natural and Social and relationship Capital. Conscious efforts are made for judicious management of these six capitals in the company. For each capital, they have decided to define some performance parameters and recording of these parameters allow them to keep an eye on their sustainability.

Sustainability Disclosure:

$\mathrm{ABC}$ Steel has been a pioneer in disclosing its sustainability performance transparently through various disclosure platforms. They have been publishing Sustainability Reports following the Global Reporting Initiative (GRI) Framework (first company in India) since 2001. In FY 2015-16 They were the first company in India to transition towards Integrated Reporting through the International Integrated Reporting Framework (IIRC). They have also been disclosing our sustainability performance to international and national platforms like world steel, Dow Jones Sustainability Index Assessment (DJSI), CDP and national level award applications amongst others. Transparency is an important trait if a company wants to gain the trust of consumers. It leaves them with an enormous number of opportunities in marketing. By implementing such techniques, ABC steel India has been able to become a leader in Indian sustainability scene and to receive a lot of applause from across the world.

They achieved a 26\% reduction in CO2 emission intensity at Plant 01 in FY05.In FY17, they brought the $\mathrm{CO} 2$ emission intensity at Plant 02 by $17 \%$.They have reduced their Net Water Consumption at Plant 01 in FY16.They utilized 100\% of the solid waste generated at Plant 01 and Plant 02 in FY19.They claim to have touched 1.2 million lives through their CSR (Corporate Social Responsibility) initiatives in FY19.From the above facts, we can see that ABC Steel is improving sustainability in all the three aspects (Environmental, Economic and Social) of it. 


\section{Conclusion}

Sustainable manufacturing is the key to achieving SDGs and for that, industry 4.0 technology is indispensable. It has a wide range of useful smart technology which can help enhance sustainability in manufacturing in an unprecedented manner. There are serious challenges also which will make this task of implementing I4.0 an uphill one. To overcome such challenges, governments will have to work with the private sector and frame policies which are well suited to this objective. Collaboration of the industry with educational institutions can be done to groom the future workforce keeping in mind the digitalization. Technical institutes may provide their quality research in the field of sustainability in manufacturing and contribute a great deal.

\section{References}

[1]. Acatech: Umsetzungsempfehlungen für das Zukunftsprojekt Industrie 4.0 - Abschlussbericht des Arbeitskreises Industrie 4.0. acatech, 2013.

[2]. Kagermann, H.; Lukas, W.; Wahlster, W: Abschotten ist keine Alternative. In: VDI Nachrichten, Issue 16, (2015).

[3]. Kagermann, H.; Lukas, W.; Wahlster, W.: Industrie 4.0 - Mit dem Internet der Dinge auf dem Weg zur 4. industriellen Revolution. In: VDI Nachrichten, Issue 13, 2011.

[4]. Pratish Rawat(1), Dr. Jayant Kishore Purohit(2), “A Review of Challenges in Implementation of Industry 4.0 in Indian Manufacturing Industry" , International Conference on Recent Trends and Innovation in Engineering, Science \& Technology ICRTIEST-2019 Dec. 20-21, 2019, ISBN: 978-93-5396-404-7 .

[5]. Ravinder Kumar, Rajesh Kr. Singh, Yogesh Kr. Dwivedi Application of Industry 4.0 technologies in Indian SMEs for sustainable growth: Analysis of challenges, Journal of Cleaner Production https://doi.org/10.1016/j.jclepro.2020.124063

[6]. Sudip Phuyala Diwakar Bistaa, Rabindra Bistab , “Challenges, Opportunities and Future Directions of Smart Manufacturing: A State of Art Review". Sustainable Futures Volume 2, 2020.

[7]. Tay Shu Ing (1), T.C. Lee(2), S.W. Chan (3), J. Alipal (4) \& N. Abdul Hamid (5), "An Overview of the Rising Challenges in Implementing Industry 4.0", Int. J Sup. Chain. Mgt, Vol. 8, No. 6, December 2019.

[8]. Viraj Vijay Jadhav I Ravindra Mahadeokar I Dr. S. D.Bhoite, "The Fourth IndustrialRevolution (I4.0) in India: Challenges \& Opportunities" Published inInternational Journal of Trend in Scientific Research and Development (ijtsrd), ISSN: 2456-6470, Special Issue I Fostering Innovation, Integration and Inclusion Through Interdisciplinary Practices in Management, March 2019, pp.105-109.

[9]. Uhlmann, E.; Fürstmann, P.; Rosenau, B.; Gebhard, S.; Gerstenberger, R.; Müller, G.: The Potential of Reducing the Energy Consumption for Machining TiAl6V4 by Using Innovative Metal Cutting Processes. In: Proceedings of the 11th Global Conference on Sustainable Manufacturing GCSM2013, 2014. 